\title{
Prognostic Factors in Patients with an Implanted Pacemaker after 80 Years of Age in a 4-Year Follow-Up
}

\author{
Krystyna Krzemień-Wolska ${ }^{a}$ Andrzej Tomasik ${ }^{b}$ Celina Wojciechowska ${ }^{b}$ \\ Karolina Barańska-Pawełczak ${ }^{a}$ Ewa Nowalany-Kozielska ${ }^{b}$ Wojciech Jacheć ${ }^{b}$ \\ ${ }^{a}$ Department of Cardiology, Szpital Specjalistyczny w Zabrzu, and ${ }^{\text {b }}$ 2nd Department of Cardiology, School of \\ Medicine with Dentistry Division in Zabrze, Medical University of Silesia, Zabrze, Poland
}

\section{Keywords}

Death · Risk factors - Cardiovascular diseases · Pacing ·

Elderly patients

\begin{abstract}
Background: The controversy over electrotherapy for patients aged $>80$ years occurs already at the stage of qualification for this treatment type and concerns optimal device selection, the implantation strategy, and the overall benefit from pacemaker therapy. The group also has a considerable number of cardiovascular risk factors, and the data from the literature on the impact of the pacing mode on the remote prognosis of this group are ambiguous. Objective: Assessment of the risk factors for death among patients with implanted pacemakers $>80$ years of age in a 4-year follow-up. Methods: The study group consisted of 140 consecutive patients (79 women) aged $84.48 \pm 3.65$ years with single- or dual-chamber pacemakers implanted $>80$ years of age because of symptomatic bradycardia. In univariate and multivariate Cox regression analyses, demographic, echocardiographic, and laboratory parameters, pharmacotherapy, and factors related to the implanted device - i.e., indications, pacemaker type, and the implantation position of the tip of the right ventricular lead - were included. The endpoint was
\end{abstract}

\section{KARGER}

(C) 2017 S. Karger AG, Basel

E-Mail karger@karger.com

www.karger.com/ger death for any reason in a 4-year follow-up. Results: During follow-up, 68 patients (48.6\%) died. Although atrial fibrillation with a slow ventricular response constituted $20 \%$ of the indications for implantation, $60.8 \%$ of the patients received a single-chamber system (VVI/VVIR). In the whole group, the multivariate Cox regression analysis showed both a favourable prognostic significance of DDD pacing system implantation ( $\mathrm{HR}=0.507 ; 95 \% \mathrm{Cl}: 0.294-0.876)$ and coexisting hypertension ( $\mathrm{HR}=0.520 ; 95 \% \mathrm{Cl}: 0.299-0.902)$. The risk factors were fasting glycaemia ( $\mathrm{HR}=1.180 ; 95 \% \mathrm{Cl}$ : 1.038-1.342) and, potentially, female sex $(\mathrm{HR}=1.672 ; 95 \% \mathrm{Cl}: 0.988-2.830$; $p=0.056$ ). In the female subgroup a more favourable prognosis was related to the use of angiotensin-converting enzyme inhibitors ( $\mathrm{HR}=0.435 ; 95 \% \mathrm{Cl}: 0.202-0.933$ ) and DDD pacemaker implantation ( $\mathrm{HR}=0.381 ; 95 \% \mathrm{Cl}$ : 0.180-0.806). In the male subgroup a more favourable prognosis was related to concerned patients with coexisting hypertension (HR $=0.349 ; 95 \% \mathrm{Cl}$ : 0.079-0.689). Conclusions: DDD mode pacing seems to serve as a factor which decreases mortality among patients aged $>80$ years in long-term follow-up. The potentially poorer prognosis for the female patients in this group may result from a combination of the dominant VVI pacing mode, potential propagation of atrial fibrillation, a low proportion of antithrombotic therapy, and sex-related predispositions to thromboembolic complications.

(c) 2017 S. Karger AG, Basel

Wojciech Jacheć, PhD

2nd Department of Cardiology, School of Medicine with Dentistry Division in Zabrze Medical University of Silesia, Maria Curie Skłodowska str. 10

PL-41-800 Zabrze (Poland)

E-Mail wjachec@interia.pl 


\section{Introduction}

An augmented life expectancy and improved therapeutic options for heart disease have increased the proportion of elderly patients requiring pacemaker implantation [1]. This is related to the pathomorphological and topographic changes occurring with ageing in the heart conduction system and a more frequent coexistence of ischaemic heart diseases or hypertension [2].

The structure and trends of mortality among the elderly as a result of cardiovascular diseases are similar to the ones observed in the whole population [3]. However, despite this observation, around $25 \%$ of clinical trials investigating effects of new methods of treatment for cardiovascular diseases still overlook this group, and recommendations for management derived from younger patients frequently lack evidence-based support for patients aged $>75$ years $[3,4]$. As a result, $\geq 80$-year-olds may have limited access to the typical treatment methods applied to younger patients.

Although clinical results tend to confirm the positive effect of physiological cardiac pacing on echocardiographic and haemodynamic parameters, as well as on exercise capacity and quality of life of the patients, a prevalence of ventricular pacing in elderly patients can still be observed [5-9].

Controversy over electrotherapy in this group occurs already at the stage of qualification for a particular form of treatment, optimal device selection, the implantation strategy, and the overall benefit from pacemaker therapy for patients $\geq 80$ years of age, since this group is burdened with many cardiovascular risk factors [10-13]. Moreover, the data from the literature on the impact of the pacing mode on long-term prognosis in this group of patients are ambiguous [6, 14-17].

The knowledge about survival - and factors having an impact on survival - among elderly patients, who constitute the most numerous group with implanted pacemakers, still remains limited and requires further study.

According to the above, in the present paper there was made an attempt to assess the impact of the type of implanted pacemaker and the position of ventricular pacing upon the prognosis of patients $>80$ years of age at implantation, taking into account coexisting risk factors and chosen echocardiographic and laboratory parameters. The aim of this paper is to assess the prognosis of patients with implanted pacemakers $>80$ years of age in a 4 -year follow-up, taking into account cardiovascular risk factors and pacing parameters.

\section{Methods}

This is a retrospective, non-randomized study providing a retrospective analysis of the clinical data on patients aged $>80$ years at implantation who had single- or dual-chamber pacemakers implanted because of symptomatic bradycardia between 2006 and 2008 in the 2nd Department of Cardiology, School of Medicine with Dentistry Division, Medical University of Silesia, Zabrze, Poland. The follow-up time was 4 years.

\section{Inclusion Criteria}

Included were patients aged $>80$ years with typical indications for cardiac pacing (atrioventricular block, sick sinus syndrome, or atrial fibrillation with slow ventricular response) and a left ventricular ejection fraction (LVEF) $>40 \%$.

\section{Exclusion Criteria}

Excluded were patients with coexisting diseases influencing life expectancy (active cancer, chronic kidney disease, abuse of alcohol or other intoxicants, poorly controlled mental illness, or acute coronary syndrome within the last 6 months).

\section{Clinical Endpoint}

Because of a lack of possibility to determine the exact cause of death of the majority of patients on the basis of the data obtained from the Polish NHS database, death for any reason was established as the endpoint. Data on death dates were obtained from the Polish NHS database.

\section{Analysed Parameters}

Demographic Data. Sex as well as age at pacemaker implantation were assessed.

Clinical Data. Indications for implantation as well as coexisting health conditions (hypertension, ischaemic heart disease, diabetes, or previous stroke) are reported. Because we do not have complete data on frailty (frailty screening tests were not performed routinely during this period at our centre), the influence of frailty on prognosis was not evaluated.

Pharmacotherapy. Use of beta-blockers, angiotensin-converting enzyme (ACE) inhibitors, AT1 receptor antagonists (angiotensin receptor blockers), thiazide and loop diuretics, statins, acetylsalicylic acid, vitamin $\mathrm{K}$ antagonists, digoxin, oral antidiabetic drugs, insulin therapy, and aldosterone antagonists was assessed.

Laboratory Parameters. Haemoglobin, creatinine, cholesterol, and sodium concentration levels are reported.

Echocardiographic Parameters. The LVEF and left ventricular end-diastolic volume were evaluated.

Data regarding Pacemakers and Pacing. The pacemaker type, pacing mode, and position of the lead tip in the right ventricle of heart were assessed. The amount of ventricular pacing (sick sinus syndrome patients) was not evaluated, because the data on pacing rates obtained from the patient records were incomplete. We could not reliably complete the data because pacemakers' memory pace rates were only present since the last device control.

\section{Statistical Analysis}

Normality of the distribution of continuous variables was assessed by means of the Shapiro-Wilk test. Continuous variables are expressed as mean values with the standard deviation; however, in the case of dichotomous variables the number of cases with the
108
Gerontology 2018;64:107-117 DOI: $10.1159 / 000481504$
Krzemień-Wolska et al. 
proportion is given. The analysis of the differences in the distribution of variables between women and men and between those who survived and those who died was performed by means of Student $t$ test distribution for continuous variables and the $\chi^{2}$ test with Yates's continuity correction for dichotomous variables.

Cox regression analysis was performed on the whole group of patients and on the subgroups divided on the basis of sex. To assess the risk of death in a long-term follow-up for the univariate Cox regression analysis, demographic, clinical, laboratory, and echocardiographic parameters and the ones related to the implanted device were taken into account. In the multivariate model the variables which reached statistical significance at $p<0.1$ in univariate analysis were analysed. The results of the univariate and multivariate Cox regression analyses for the variables which reached $p<0.1$ in the univariate analysis are presented in the figures. In the univariate and multivariate regressions, complete data were used.

In the univariate and multivariate analyses, risk of death was presented as hazard ratio (HR) with the $95 \%$ confidence interval (CI). Data concerning mortality are presented as raw data. An ageadjusted analysis was also performed, but the obtained results did not differ from the raw data.

The probability of sex-dependent survival was assessed by the Kaplan-Meier method, and the significance of the differences in shapes of curves was assessed with the log-rank test. Data from the Polish Central Statistical Office were used to estimate 4-year survival in the age-matched population (stat.gov.pl).

Differences were considered to be statistically significant at $p<$ 0.05 or if the $95 \%$ CI did not comprise 1 . If a $p$ value was between 0.05 and 0.1 , it was marked as "ns" in the text. All the statistical analyses were performed by means of the STATISTICA 10.0 programme.

Local Bioethics Committee Approval

After presentation of the study outline, the local bioethics committee gave its opinion, which stated that the planned retrospective analysis of trial outcomes does not constitute a medical experiment pursuant to the Medical Profession Act; hence no assessment of the committee was required.

\section{Results}

Among 621 patients with a pacing system implanted for the first time between 2006 and 2008, the inclusion criteria were met by 140 ( 79 women) aged $84.48 \pm 3.65$ years. In the whole group, the most common indication for pacemaker implantation was sick sinus syndrome (44.2\%); the rarest indication was atrial fibrillation with a slow ventricular response (20.0\%). However, in $60.7 \%$ of the patients a single-chamber pacemaker was implanted. An apical position of the tip of the right ventricular lead prevailed $(n=104 ; 74.3 \%)$. In nearly half of the patients, coronary artery disease was diagnosed, and in every third patient hypertension. In all, $16.4 \%$ suffered from diabetes. With regard to pharmacotherapy, nearly half of the patients used ACE inhibitors, beta-blockers, or antiplatelet

Prognostic Factors after 80 Years of Age drugs. Thiazide and loop diuretics were used by $28.6 \%$ of the patients overall. The mean LVEF was $47.98 \%$. In the laboratory tests, slightly decreased mean haemoglobin concentrations and increased creatinine and fasting glucose concentrations were observed (Table 1).

The female and male subgroups did not differ in age, indications for pacing, and the number of additional health conditions, with the exception of diabetes, which occurred more frequently in the female group. In the female group, an apical position of the tip of the right ventricular lead prevailed. In this group, antiplatelet drugs and statins were used less often. They also had a higher mean total cholesterol concentration $(p<0.001)$ (Table 1$)$.

During the 4-year follow-up, 68 patients died (48.6\%); 42 of them were women. According to the Polish Central Statistical Office data from 2000, there were 75.2 deaths per 1,000 people in the age group of 80 - to 84 -year-olds. In the subsequent years, this number gradually declined to 74.8 deaths in 2010 and 74.3 deaths in 2013. Similarly, in the group of people $>85$ years of age, in 2000 there were 189.4 deaths, in 2010 there were 159.6, and in 2013 there were 155.1 deaths. According to the above indicators (with data from 2010), the estimated 4-year survival in the agematched population should be $66.6 \%$ and was better than that of the study group $(p<0.05)$. The cumulative survival curve for all the patients and the estimated survival of the age-matched population are presented in Figure 1.

Six deaths occurred during the 30-day follow-up (all patients with a VVI pacemaker). Of these 6 deaths, 4 occurred during the hospitalization period. The 30-day mortality data are presented in Table 2.

No statistically significant differences in the age of the patients were observed between the group of patients who survived and the ones who died during the 4-year followup. In the group which achieved the endpoint, women prevailed $(p=0.051)$. The predominant indication for implantation was sick sinus syndrome $(p<0.05)$, and the VVI pacing mode prevailed $(p<0.05)$. ACE inhibitors were used significantly less frequently $(p<0.01)$. In the fatal outcome group, fewer patients suffered from hypertension $(p=0.066)$. Although the proportion of patients with diabetes was comparable between the two subgroups, a higher mean fasting glucose concentration was observed in the deceased patients $(p<0.05)$. What is more, this group had a lower haemoglobin concentration $(p<0.05)$ (Table 1$)$.

\section{Univariate Cox Regression Analysis}

This assessment was made for the whole group of patients and for the male and female subgroups. In the 
Table 1. Characteristics of the study population stratified by patients' gender and prognosis

\begin{tabular}{|c|c|c|c|c|c|c|c|}
\hline & $\begin{array}{l}\text { All patients } \\
n=140 \\
(100 \%)\end{array}$ & $\begin{array}{l}\text { Male } \\
n=61 \\
(43.57 \%)\end{array}$ & $\begin{array}{l}\text { Female } \\
n=79 \\
(56.43 \%)\end{array}$ & $p ; \mathrm{M}$ vs. $\mathrm{F}$ & $\begin{array}{l}\text { Dead } \\
n=68 \\
(48.6 \%)\end{array}$ & $\begin{array}{l}\text { Survivors } \\
n=72 \\
(51.4 \%)\end{array}$ & $p$; D vs. S \\
\hline Female & $79(56.43)$ & & & & $42(61.8)$ & $27(37.5)$ & 0.057 \\
\hline Age, years & $84.48 \pm 3.65$ & $84.48 \pm 3.50$ & $84.48 \pm 3.78$ & ns & $85.21 \pm 4.27$ & $83.79 \pm 2.81$ & ns \\
\hline Dead & $68(48.6)$ & $26(42.6)$ & $42(53.2)$ & ns & & & \\
\hline \multicolumn{8}{|c|}{ Type of pacemaker and right ventricular lead tip location } \\
\hline $\mathrm{DDD} /$ & $55(39.3) /$ & $26(42.6) /$ & $29(36.7) /$ & ns & $19(27.9) /$ & $36(50.0) /$ & $<0.05$ \\
\hline VVI & $85(60.7)$ & $35(57.4)$ & $50(63.3)$ & & $49(72.1)$ & $36(50.0)$ & \\
\hline VVI ARVLL/ & $66(77.6) /$ & $23(37.7) /$ & $43(54.4) /$ & $<0.05$ & $38(55.9) /$ & $28(38.9) /$ & ns \\
\hline n-ARVLL & $19(22.4)$ & $12(19.7)$ & $7(8.9)$ & & $11(16.2)$ & $8(11.1)$ & \\
\hline DDD ARVLL/ & $38(69.1) /$ & $15(24.6) /$ & $23(29.1) /$ & 0.083 & $12(17.6) /$ & $26(33.3) /$ & ns \\
\hline n-ARVLL & $17(30.9)$ & $11(18.0)$ & $6(7.6)$ & & $7(10.3)$ & $10(13.9)$ & \\
\hline All PM ARVLL/ & $104(74.3) /$ & $38(62.3) /$ & $66(83.5) /$ & $<0.01$ & $50(73.5) /$ & $54(75.0) /$ & ns \\
\hline n-ARVLL & $36(25.7)$ & $23(37.7)$ & $13(16.5)$ & & $18(26.5)$ & $18(25.0)$ & \\
\hline \multicolumn{8}{|c|}{ Cardiac conduction system and concomitant diseases } \\
\hline A-V block & $50(35.7)$ & $25(41.0)$ & $25(31.7)$ & ns & $20(29.4)$ & $30(41.7)$ & ns \\
\hline $\mathrm{AF}$ & $28(20.0)$ & $11(18.0)$ & $17(21.5)$ & ns & $10(14.7)$ & $18(25.0)$ & ns \\
\hline SSS (all) & $62(44.2)$ & $25(41.0)$ & $37(46.8)$ & ns & $38(55.9)$ & $24(37.5)$ & $<0.05$ \\
\hline SSS (VVI) & $46(32.9)$ & $19(31.1)$ & $27(34.2)$ & ns & $30(44.1)$ & $16(22.2)$ & $<0.05$ \\
\hline $\mathrm{CAD}$ & $48(34.3)$ & $25(41.0)$ & $23(29.1)$ & ns & $22(32.4)$ & $26(36.1)$ & ns \\
\hline History of arterial hypertension & $60(42.9)$ & $23(37.7)$ & $37(46.8)$ & ns & $22(32.4)$ & $38(52.8)$ & 0.066 \\
\hline T2DM & $23(16.4)$ & $5(8.2)$ & $18(22.8)$ & $<0.05$ & $12(17.6)$ & $11(15.3)$ & ns \\
\hline History of stroke & $9(6.4)$ & $5(8.2)$ & $4(5.06)$ & ns & $4(5.88)$ & $5(6.94)$ & ns \\
\hline \multicolumn{8}{|l|}{ Medical treatment } \\
\hline $\mathrm{BB}$ & $63(45.0)$ & $27(44.3)$ & $36(45.6)$ & ns & $28(41.2)$ & $35(48.6)$ & ns \\
\hline ACE-I & $65(46.4)$ & $33(54.1)$ & $32(40.5)$ & ns & $23(33.8)$ & $42(58.3)$ & $<0.01$ \\
\hline $\mathrm{ARB}$ & $3(2.1)$ & $2(3.28)$ & $1(1.27)$ & ns & $1(1.47)$ & $2(2.78)$ & ns \\
\hline Statins & $32(22.9)$ & $19(31.2)$ & $13(16.5)$ & $<0.05$ & $11(16.2)$ & $21(29.2)$ & ns \\
\hline TD & $20(14.3)$ & $8(13.1)$ & $12(15.2)$ & ns & $6(8.82)$ & $14(19.4)$ & ns \\
\hline TLD & $20(14.3)$ & $9(14.8)$ & $11(13.9)$ & ns & $12(17.6)$ & $8(11.1)$ & ns \\
\hline ASS & $65(46.4)$ & $34(55.7)$ & $31(39.2)$ & 0.052 & $26(38.2)$ & $39(54.2)$ & 0.086 \\
\hline AVK & $10(7.1)$ & $4(6.56)$ & $6(7.59)$ & ns & $4(5.88)$ & $6(8.33)$ & ns \\
\hline Nitrate & $32(22.9)$ & $17(27.9)$ & $15(19.0)$ & ns & $13(19.1)$ & $19(26.4)$ & ns \\
\hline Digoxin & $13(9.3)$ & $6(9.84)$ & $7(8.86)$ & ns & $7(10.3)$ & $6(8.33)$ & ns \\
\hline $\mathrm{AA}$ & $24(17.1)$ & $12(19.7)$ & $12(15.2)$ & ns & $14(20.6)$ & $10(13.9)$ & ns \\
\hline Oral HD & $14(10.0)$ & $5(8.20)$ & $9(11.4)$ & ns & $8(11.8)$ & $6(8.33)$ & ns \\
\hline Insulin therapy & $9(6.43)$ & $1(1.64)$ & $8(10.1)$ & $<0.05$ & $5(7.35)$ & $4(5.56)$ & \\
\hline \multicolumn{8}{|l|}{ Echocardiographic parameters } \\
\hline LVEDV, mL & $81.27 \pm 25.17$ & $85.3 \pm 28.6$ & $78.3 \pm 22.0$ & ns & $78.4 \pm 24.9$ & $83.9 \pm 25.5$ & ns \\
\hline LVEF, \% & $47.98 \pm 7.63$ & $47.1 \pm 8.48$ & $48.6 \pm 6.94$ & ns & $48.19 \pm 7.78$ & $47.8 \pm 7.57$ & ns \\
\hline \multicolumn{8}{|l|}{ Laboratory parameters } \\
\hline Haemoglobin, g/dL & $12.8 \pm 1.67$ & $13.00 \pm 1.74$ & $12.61 \pm 1.61$ & ns & $12.42 \pm 1.74$ & $13.1 \pm 1.55$ & $<0.05$ \\
\hline Creatinine, $\mu \mathrm{mol} / \mathrm{L}$ & $98.4 \pm 34.4$ & $98.7 \pm 21.6$ & $98.14 \pm 45.2$ & ns & $102.3 \pm 43.5$ & $94.7 \pm 28.2$ & ns \\
\hline Fasting glucose, $\mathrm{mmol} / \mathrm{L}$ & $5.90 \pm 1.80$ & $5.99 \pm 1.59$ & $5.83 \pm 1.96$ & ns & $6.27 \pm 2.08$ & $5.57 \pm 1.44$ & $<0.05$ \\
\hline Cholesterol, $\mathrm{mg} \%$ & $180.1 \pm 46.0$ & $164.3 \pm 39.8$ & $193.3 \pm 46.9$ & $<0.001$ & $172.5 \pm 4.91$ & $186.1 \pm 4.29$ & ns \\
\hline Sodium, $\mathrm{mmol} / \mathrm{L}$ & $139.0 \pm 3.87$ & $139.0 \pm 3.84$ & $139.0 \pm 3.92$ & ns & $139.1 \pm 4.44$ & $138.9 \pm 3.30$ & ns \\
\hline
\end{tabular}

Values are mean \pm SD or $n(\%)$. ns, non-significant; D, dead; S, survivors; DDD, dual-chamber pacemaker; VVI, single-chamber pacemaker; ARVLL, apical right ventricular lead location; n-ARVLL, non-apical right ventricular lead location; PM, pacemaker; A-V block, atrial-ventricular block (degrees II and III); AF, atrial fibrillation; SSS, sick sinus syndrome; CAD, coronary artery disease; T2DM, type 2 diabetes mellitus; BB, beta-blocker; ACE-I, angiotensin-converting enzyme inhibitor; ARB, angiotensin receptor blocker; TD, thiazide derivative diuretic; TLD, loop diuretic; ASS, acetylsalicylic acid; AVK, oral anticoagulant; AA, aldosterone antagonist; Oral HD, oral hypoglycaemic therapy; LVEDV, left ventricular end-diastolic volume; LVEF, left ventricular ejection fraction.

$110 \quad$ Gerontology 2018;64:107-117 DOI: $10.1159 / 000481504$

Krzemień-Wolska et al. 
Table 2. Thirty-day mortality

\begin{tabular}{|c|c|c|c|c|c|c|c|c|c|c|}
\hline & $\begin{array}{l}\text { Initials } \\
\text { gender }\end{array}$ & $\begin{array}{l}\text { Age, } \\
\text { years }\end{array}$ & Diagnosis & $\begin{array}{l}\text { Date of } \\
\text { implantation }\end{array}$ & $\begin{array}{l}\text { PM } \\
\text { system }\end{array}$ & $\begin{array}{l}\mathrm{Hb}, \\
\mathrm{g} / \mathrm{dL}\end{array}$ & $\begin{array}{l}\text { Creatinine, } \\
\mu \mathrm{mol} / \mathrm{L}\end{array}$ & $\begin{array}{l}\text { Date } \\
\text { of death }\end{array}$ & Cause of death & $\begin{array}{l}\text { Oral } \\
\text { anticoagulation }\end{array}$ \\
\hline 1 & $\begin{array}{l}\text { G.J. } \\
\text { female }\end{array}$ & 91.3 & $\mathrm{AF}$ & 17 June 2008 & VVI & 10.7 & 90.8 & 11 July 2008 & $\begin{array}{l}\text { ischaemic } \\
\text { stroke }\end{array}$ & no \\
\hline 2 & $\begin{array}{l}\text { J.M. } \\
\text { female }\end{array}$ & 82.7 & $\begin{array}{l}\text { A-V } \\
\text { block }\end{array}$ & 4 July 2007 & VVI & 12.9 & 177.2 & 7 July 2007 & pneumonia & no \\
\hline 3 & $\begin{array}{l}\text { M.R. } \\
\text { female }\end{array}$ & 94.4 & $\begin{array}{l}\text { A-V } \\
\text { block }\end{array}$ & 17 June 2007 & VVI & 13.9 & 122.2 & 18 June 2007 & $\begin{array}{l}\text { pneumothorax } \\
\text { multi-organ } \\
\text { failure }\end{array}$ & no \\
\hline 4 & $\begin{array}{l}\text { Z.S. } \\
\text { female }\end{array}$ & 91.6 & AFL & 5 June 2007 & VVI & 12.2 & 88.2 & 29 June 2007 & $\begin{array}{l}\text { ischaemic } \\
\text { stroke }\end{array}$ & no \\
\hline 5 & $\begin{array}{l}\text { J.S. } \\
\text { male }\end{array}$ & 82.2 & $\mathrm{AF}$ & 18 July 2007 & VVI & 10.6 & 132.1 & 21 July 2007 & $\begin{array}{l}\text { ischaemic } \\
\text { stroke }\end{array}$ & no \\
\hline 6 & $\begin{array}{l}\text { L.W. } \\
\text { female }\end{array}$ & 81.3 & $\begin{array}{l}\text { A-V } \\
\text { block }\end{array}$ & 6 October 2006 & VVI & 10.8 & 85.3 & 6 October 2006 & $\begin{array}{l}\text { ischaemic } \\
\text { stroke }\end{array}$ & no \\
\hline
\end{tabular}

PM, pacemaker; Hb, haemoglobin; AF, atrial fibrillation; A-V block, atrial-ventricular block (degrees II and III); AFL, atrial flutter; VVI, single-chamber pacemaker.

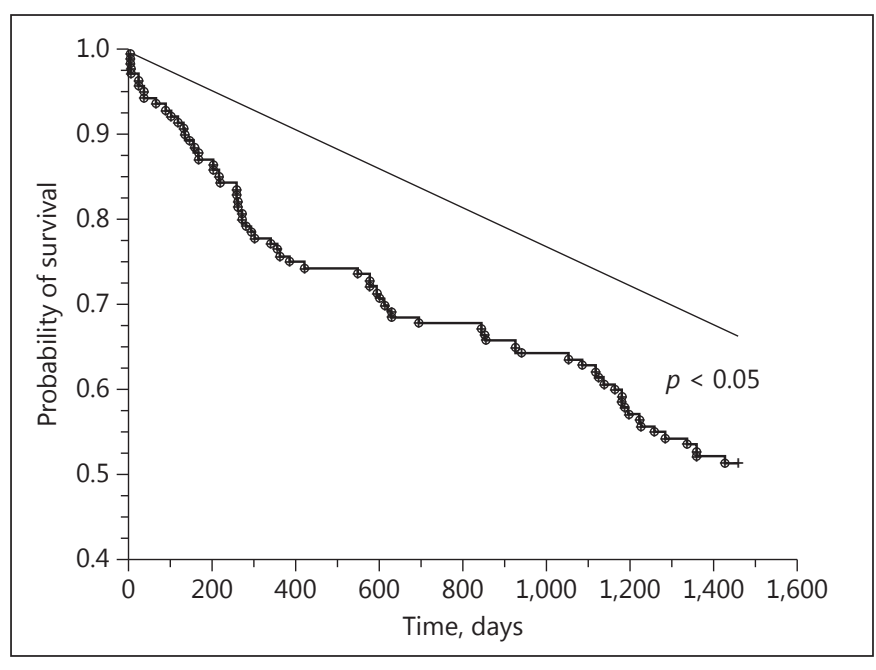

Fig. 1. Cumulative Kaplan-Meier survival curve for the whole group of patients with implanted pacemakers $>80$ years of age in the 4-year follow-up period and estimation of 4-year survival in the age-matched population (solid line).

whole group, the univariate Cox regression analysis proved that the coexistence of hypertension $(\mathrm{HR}=0.527$; $p<0.05)$, dual-chamber pacemaker implantation $(\mathrm{HR}=$ $0.473 ; p<0.01)$, ACE inhibitor use $(\mathrm{HR}=0.467 ; p<0.01)$,

Prognostic Factors after 80 Years of Age acetylsalicylic acid use $(\mathrm{HR}=0.601 ; p<0.05)$, and an increased haemoglobin concentration ( $\mathrm{HR}=0.836$; $p<$ $0.05)$ were positive prognostic factors. A potentially positive prognosis involved the use of statins $(\mathrm{HR}=0.537$; $p=0.060)$.

Negative prognostic factors were a higher age at implantation $(\mathrm{HR}=1.078 ; p<0.05)$ and increased fasting glucose levels $(\mathrm{HR}=1.189 ; p<0.01)$. Female sex was a negative prognostic factor of borderline statistical significance $(\mathrm{HR}=1.513 ; p=0.097)$.

In the female subgroup, a potentially favourable prognostic significance was correlated with dual-chamber pacemaker implantation ( $\mathrm{HR}=0.416 ; p<0.05)$, use of ACE inhibitors $(\mathrm{HR}=0.412 ; p<0.05)$, and an elevated haemoglobin concentration ( $\mathrm{HR}=0.818 ; p<0.05)$. A potentially favourable prognosis was related to the use of acetylsalicylic acid (HR $=0.409 ; p=0.061)$ and nitrates $(\mathrm{HR}=0.409 ; p=0.061)$. An increased fasting glucose concentration $(\mathrm{HR}=1.202 ; p<0.05)$ had a negative prognostic significance.

In the male group, coexisting hypertension $(\mathrm{HR}=0.214$; $p<0.01)$ was a positive prognostic factor. The correlation of an elevated cholesterol concentration with a reduced probability of death was of borderline statistical significance $(\mathrm{HR}=0.881 ; p=0.086)$ (Fig. 2). The other parameters, presented in Table 1, were of no prognostic significance. 


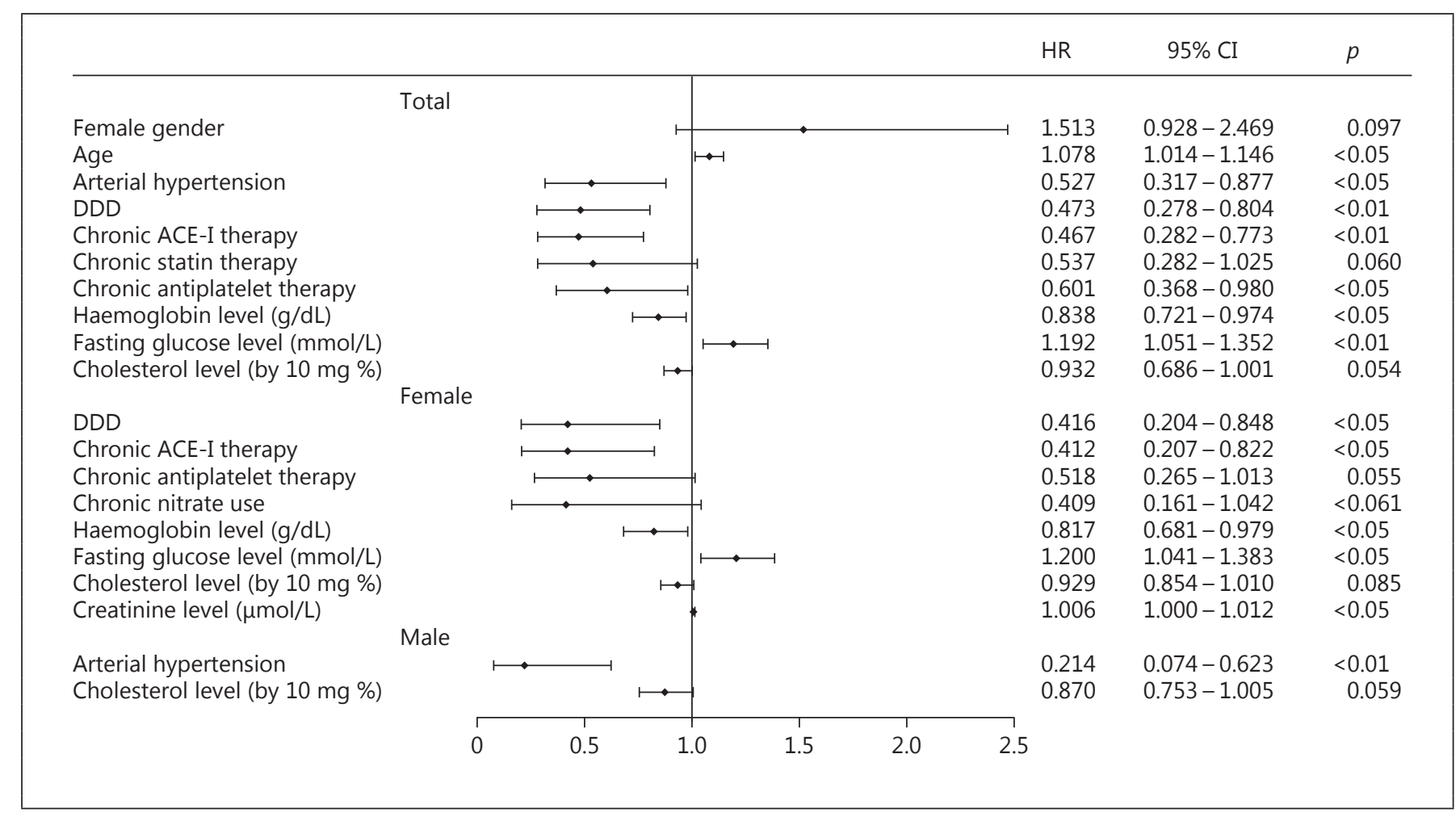

Fig. 2. Mortality risk factors of the patients with implanted pacemakers $>80$ years of age over a 4 -year follow-up period. Univariate Cox regression model. ACE-I, angiotensin-converting enzyme inhibitor.

Multivariate Cox Regression and the log-Rank Test

The multivariate model involved variables whose $p$ value in the univariate analysis was $<0.1$. In the whole group of patients, a protective effect was induced by the coexistence of hypertension ( $\mathrm{HR}=0.52 ; p<0.05)$, dualchamber pacemaker implantation $(\mathrm{HR}=0.507 ; p<0.05)$, and an increased haemoglobin concentration ( $\mathrm{HR}=$ $0.846 ; p<0.05)$. Adverse prognostic factors were an increased fasting glucose concentration $(\mathrm{HR}=1.180 ; p<$ $0.05)$ and female sex, which reached borderline statistical significance $(\mathrm{HR}=1.672 ; p=0.056)$.

In the female group, a more favourable prognosis was observed in the patients who had a dual-chamber pacemaker implanted $(\mathrm{HR}=0.381 ; p<0.05)$ and in those who used ACE inhibitors (HR $=0.435 ; p<0.05)$. The haemoglobin concentration level reached borderline statistical significance $(\mathrm{HR}=0.826 ; p=0.082)$. A mortality risk factor was elevated fasting glucose $(\mathrm{HR}=1.193 ; p<0.05)$. In the male group, a more favourable prognosis was observed in patients with diagnosed hypertension ( $\mathrm{HR}=$ $0.349 ; p<0.01$ ) (Fig. 3).

\section{Kaplan-Meier Survival Analysis}

The Kaplan-Meier survival analysis proved a better prognosis for the male group (log-rank $p<0.05)$ and for the group with dual-chamber pacemakers implanted $(\log$-rank $p<0.05)$ (Fig. 4, 5).

\section{Discussion}

The prognostic advantage of the DDD mode and the potentially worse survival in the female group after pacemaker implantation are the basic findings of this study. The adverse prognosis correlated also with a lower haemoglobin concentration and higher fasting glucose (in the female subgroup as well). Improved survival was observed also among patients with coexisting hypertension (in the male subgroup as well). Women benefited from ACE inhibitor therapy too.

The distribution of parameters in the study group (sex, age, and additional health conditions analysed) was comparable to that in previously examined populations of $>80$-year-olds $[5,6,14,15,18-20]$. In contrast to the pre- 


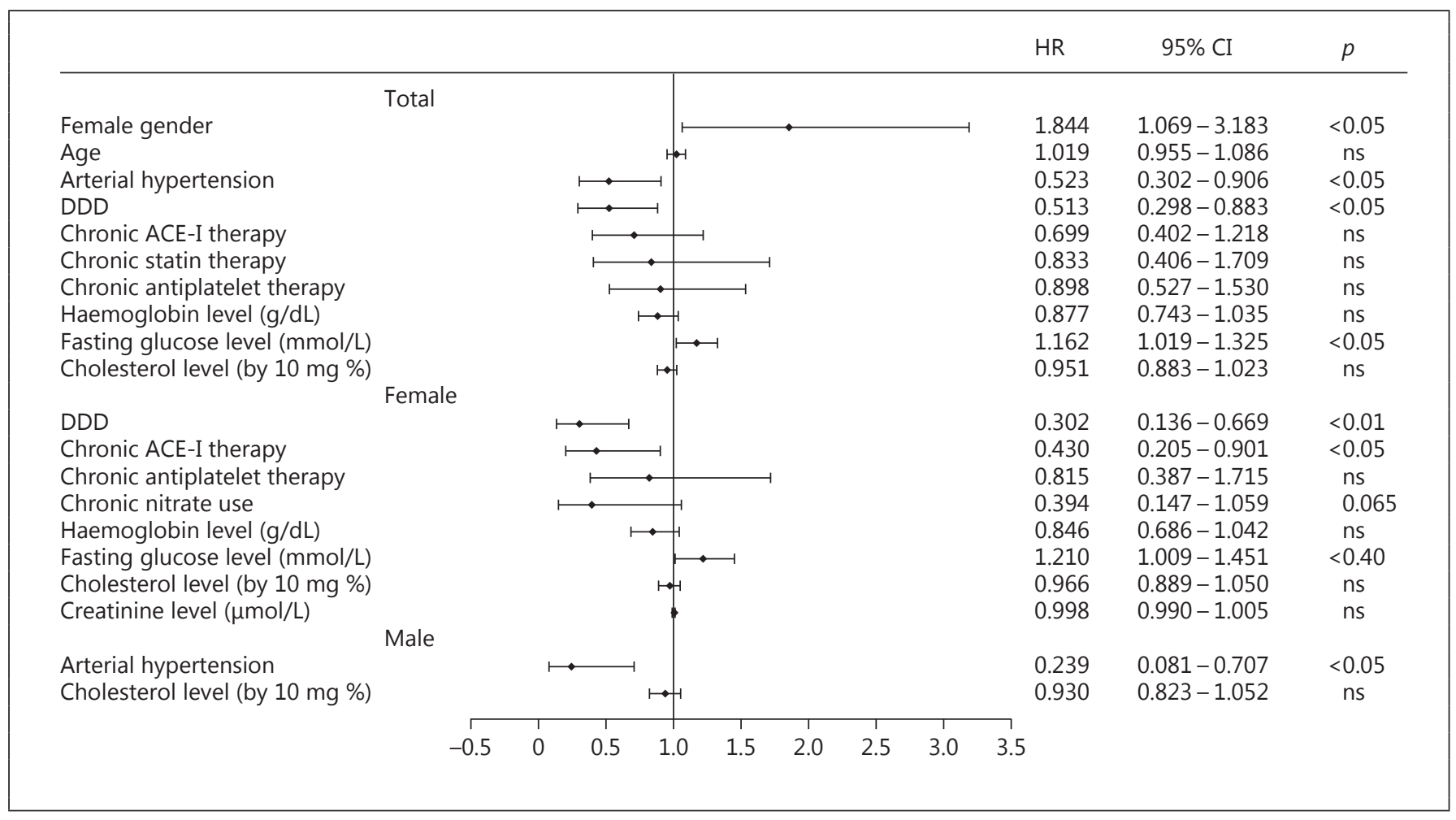

Fig. 3. Mortality risk factors of the patients with implanted pacemakers $>80$ years of age over a 4 -year follow-up period. Multivariate Cox regression model. ACE-I, angiotensin-converting enzyme inhibitor.

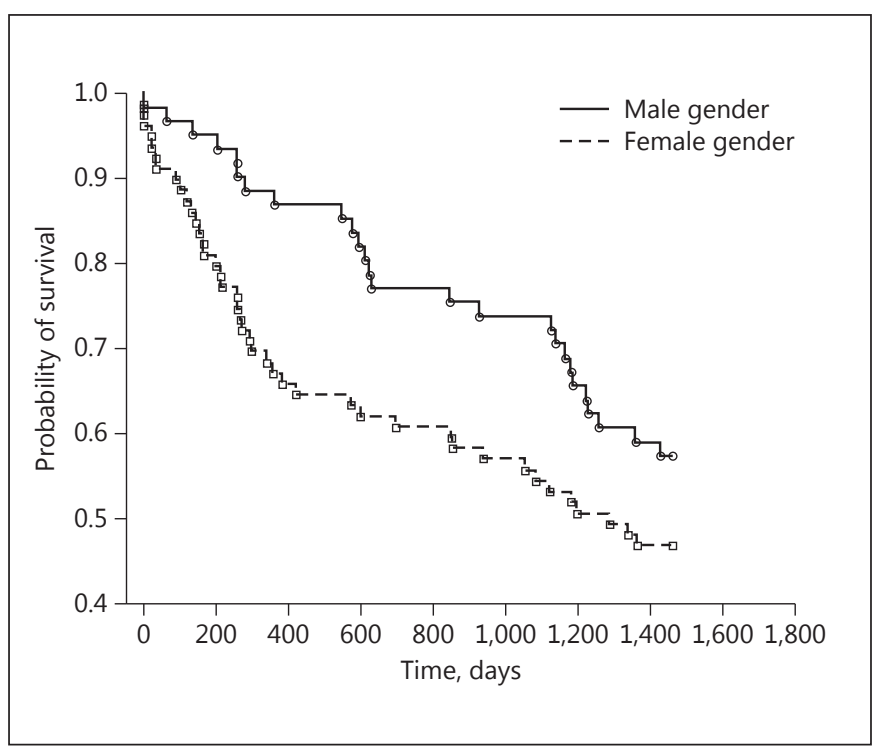

Fig. 4. Kaplan-Meier survival curves for the patients with implanted pacemakers $>80$ years of age depending on gender over a 4 -year follow-up period.

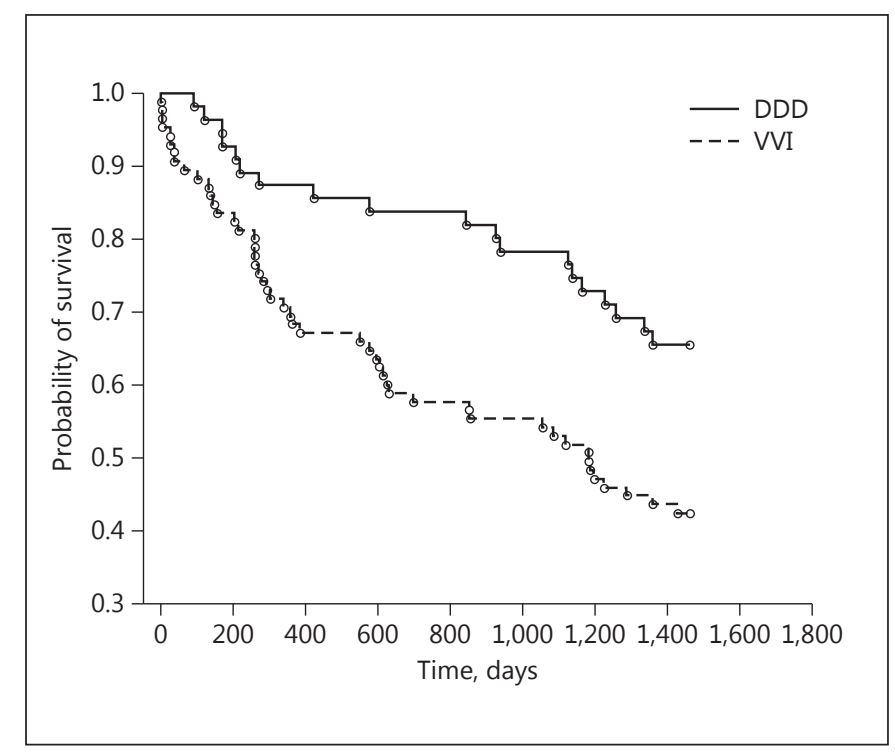

Fig. 5. Kaplan-Meier survival curves for the patients with implanted pacemakers $>80$ years of age depending on the mode of pacing over a 4-year follow-up period. 
viously quoted research studies, in this paper pharmacotherapy and selected laboratory parameters were analysed as well. The basic indication for pacemaker implantation was sick sinus syndrome, whereas in the previous research $\mathrm{A}-\mathrm{V}$ conduction disorders prevailed $[6,14,15$, $20]$. The majority of the patients $(60.7 \%)$ had VVI pacemakers implanted. This proportion is coincident with data presented in other studies $[5,6]$.

In 1966 Samet et al. [7] demonstrated a beneficial effect of the DDD mode on haemodynamic parameters. In comparison with VVI pacing it is better tolerated, improves quality of life, and prevents atrial fibrillation episodes and development of heart failure $[8,9,11,16]$. In a retrospective analysis in 1995, Lamas et al. [21] noted a positive impact of physiological pacing on mortality reduction in the very elderly.

These observations found no confirmation in the first randomized study on the impact of pacing mode upon remote prognosis in the elderly. A positive impact of atrial pacing on atrial fibrillation episodes and thromboembolic complications was observed; however, it did not considerably influence survival during the study's 3.3-year followup period [18]. After extension of the follow-up time to 8 years, a significantly higher cardiovascular and total mortality was noted in the group with VVI pacemakers [19]. Further studies confirmed the favourable impact of the dual-chamber system upon quality of life, exercise capacity, and sinus rhythm stabilization, as well as a decrease in the number of atrial fibrillation episodes, strokes, and instances of heart failure. However, in the CTOP, MOST, and UK-PACE studies, no improved survival was observed in elderly patients with atrioventricular block and an implanted dual-chamber pacemaker [17, 22-24].

In the present study, during the 4-year follow-up 68 patients died (48\%). This proportion is comparable with those reported in other papers, where the mortality rate during a 5 -year follow-up was between 45 and $58 \%$ [14, $16,20,25$ ]. Jahangir et al. [6] showed that 5-year survival among patients with implanted single-chamber pacemakers was at the level of $45 \%$ and was statistically significantly lower than among patients with implanted dual-chamber pacemakers (58\%). In that study, the sex factor did not determine the choice of the pacing mode. Nevertheless, among the patients who qualified for VVI implantation, a statistically significantly greater frequency of occurrence of additional health conditions (diabetes, stroke, and organic brain syndrome) was observed. Dual-chamber pacemakers were more frequently implanted in patients after cardiothoracic surgeries. In their univariate analysis, the authors demonstrated an adverse effect of the VVI mode in comparison to the DDD mode on patients with atrioventricular block. This was not confirmed in their multivariate analysis. According to the multivariable regression analysis, independent predictors of all-cause mortality were the number of co-morbidities (angina, cardiomyopathy, paroxysmal atrial fibrillation, diabetes mellitus, and stroke/transient ischaemic attack were not significant predictors), New York Heart Association functional class, left ventricular systolic dysfunction, and older age at implantation [6].

The survival analysis by Shen et al. [26] revealed that factors increasing mortality in the elderly were heart failure, chronic obstructive pulmonary disease, advanced age, $\mathrm{A}-\mathrm{V}$ conduction disorders, and a history of syncope. In their retrospective study, Schmidt et al. [14] showed that VVI pacemaker implantation correlates with a $42 \%$ increase in risk of death in remote observation (HR 1.42; 95\% CI: 1.12-1.81). Other adverse prognostic factors were an age at implantation $>85$ years and male sex.

Udo et al. [20] noted a 51\% mortality rate during their 5 -year follow-up in a comparable age group. The authors did not demonstrate the impact of pacing mode on remote prognosis. The predominant indication for pacemaker implantation was atrioventricular block, while atrial fibrillation with a slow ventricular response was observed at nearly the same level as in this paper (20\%). The authors did not analyse the impact of pharmacotherapy (with the exception of anticoagulants and antiplatelet drugs altogether) and of additional test results on remote prognosis. In their multivariate regression analysis, they proved that risk factors for death were male sex, older age at implantation, diabetes, congestive heart failure, and coronary artery disease. A prognostic significance of physiological pacing was not confirmed. An adverse prognostic significance of VVI pacing in a group of $>70$-year-olds was shown by Pyatt et al. [27].

Although hypertension is a confirmed factor for other cardiovascular conditions [28], it was observed that its presence in elderly patients correlates with a more favourable prognosis [29-31]. It is possible that high blood pressure (BP) is a marker of physiologic vigour or that a normal BP in some persons may be due to lowering of BP as a result of cardiovascular or other diseases. Our results confirm the above observations. In this study group, hypertension correlated with $48 \%(\mathrm{HR}=0.52$; 95\% CI: $0.299-0.902)$ and $65.1 \%(\mathrm{HR}=0.349$; 95\% CI: 0.079 0.689 ) decreases in mortality probability in the whole group and in the male group, respectively, during the 4-year follow-up period.
114

Gerontology 2018;64:107-117

DOI: $10.1159 / 000481504$
Krzemień-Wolska et al. 
In contrast to the results from the papers quoted above, we observed a borderline statistically significant adverse impact of female sex upon remote prognosis after pacemaker implantation. According to our results, a $67.2 \%$ increase in mortality risk among women was observed $(\mathrm{HR}=1.672$; 95\% CI: 0.988-2.830; $p=0.056)$. Premenopausal women are diagnosed with cardiovascular diseases much more rarely than men. In post-menopause, female sex ceases to be a protective factor. The number of cardiovascular conditions increases substantially and reaches the level observed among men. Female sex is also an independent factor for stroke and thromboembolic complications in patients with atrial fibrillation [32].

In the study group, chronic atrial fibrillation was observed in $20 \%$ of the patients $(21.5 \%$ of the women and $18.0 \%$ of the men) and oral antithrombotic therapy was used by only $7.1 \%$ of the patients at the beginning of the observation period. Moreover, nearly half of the patients were people suffering from sick sinus syndrome, in which paroxysmal atrial fibrillation is often observed. To complete the picture, it is crucial to add that the number of implantations of single-chamber devices $(60.7 \%)$ was disproportionately high compared to the medical indications (20\% patients only with atrial fibrillation with a slow ventricular response); VVI stimulation predisposes to occurrence of atrial fibrillation in patients with a preserved sinus rhythm $[11,16]$.

Despite the comparable proportion of VVI pacemaker implantations in the women and the men, an adverse apical position of the ventricular lead tip prevailed among the women ( 54.4 vs. $37.7 \%$ ). Women suffered from diabetes significantly more often; they also required insulin therapy far more often, and they were prescribed statins less frequently. There is a high probability that the accumulation of the above-mentioned risk factors may be responsible for the adverse prognosis in women.

Another population in which female sex correlated with worse prognosis were patients after aortic procedures. Di Luozzo et al. [33] noted a worse prognosis for females in a group of patients who had survived a year after repair of a descending and thoracoabdominal aortic aneurysm, although the survival rate in the whole group was similar to that in a matched New York State population. The female patients were twice as likely to die as the comparable population. The authors explained this with a low BMI $(<23)$, which was a significant factor for death in the female group.

In our study group, diabetes had no prognostic significance; however, impaired fasting glucose was an adverse prognostic factor both in the whole group and in the female subgroup.

Prognostic Factors after 80 Years of Age
Frailty is a common risk factor in the elderly. Its prevalence is estimated $<10 \%$ in populations aged $60-69$ years [34], but among long-lived individuals ( $>80$ years) the frailty index ranges from 16 to $26 \%$ [35]. Green et al. [36] analysed the cohort of 83,792 Medicare patients aged $>65$ years from the National Cardiovascular Data Registry who underwent first primary prevention implantable cardioverter defibrillator implantation. Ten percent of the patients had frailty. The 1 -year mortality rate was $22 \%$ among the patients with frailty and $12 \%$ in the overall cohort.

Based on the above data, it can be estimated that the maximum number of patients with frailty in our study group did not exceed 37 persons. In the present work, due to incomplete data the impact of frailty on prognosis was not analysed.

Anaemia is another risk factor in the elderly [37-41] and this risk is not accounted for by an underlying disease [41]. The Cardiovascular Health Study revealed a link between anaemia and frailty and showed that the prevalence of frailty significantly increased as the haemoglobin level declined [42]. Declines in cognitive [43] and executive function [44] are associated with anaemia in older women too.

In the present study, a lower haemoglobin concentration was considered a risk factor for death in all patients and in the female patients under univariate Cox regression analysis, but in the multivariate analysis this parameter was not statistically significant.

An important observation was the protective effect of ACE inhibitors on survival, especially in the female subgroup. This is vital, since patients with a preserved or slightly reduced LVEF ( $>40 \%$ ) qualified for the study. Heart failure symptoms were not advanced; loop diuretics were used by 20 patients (14.3\%). Both the LVEF and the necessity of using loop diuretics had no prognostic significance. The results confirm the significance of ACE inhibitors in clinical trials of the elderly, which is documented, for instance, in the HOPE study [45]. The present study provides further results documenting the benefits which elderly patients gain from physiological pacing.

\section{Conclusions}

Implantation of dual-chamber pacemakers in elderly patients does not correlate with a higher frequency of technical difficulties when compared to younger people, but patients $\geq 75$ years of age are at an increased risk of

Gerontology 2018;64:107-117 DOI: $10.1159 / 000481504$ 
early post-implantation complications (pneumothorax, both atrial and ventricular lead dislodgement, or loss of capture). Early complication rates are higher among patients receiving atrial-based pacemakers [46]. Singlechamber VVI/VVIR pacemakers feature a longer service life and are less expensive and potentially easier to implant and monitor than dual-chamber pacemakers. Despite the longer service life of the batteries, they do not in contrast to the dual-chamber systems - assure atrioventricular synchrony and they can cause pacemaker syndrome. This is why advanced age should not serve as the only criterion for disqualification from dual-chamber pacemaker implantation.

In the present study, $60.7 \%$ of the patients had received VVI pacemakers, while atrial fibrillation with a slow ventricular rate was detected in $20 \%$ of them. Guidelines from 2007 suggest AAIR (class I level of evidence C) or DDDR mode (class IIa/IIb level of evidence C) pacemakers for patients with sinus node dysfunction [47]. The present data show that there were significant deviations from these recommendations in the case of elderly individuals; however, this issue does not concern only the oldest people.

Data obtained from the Italian Pacemaker Registry showed that in a comparable period of time, $37 \%$ of the patients (aged 0 to $>90$ years) were implanted with VVI/ VVIR pacemakers, while atrial fibrillation with a slow ventricular rate was the cause of pacemaker implantation in only $18 \%$ of them [48].

It is crucial that in elderly patients the choice of the pacing mode is one of few modifiable risk factors which exert a great impact. In the present study group, dual- chamber pacemaker implantation correlated with a nearly $50 \%$ lower risk of death within the 4 -year follow-up. In the female subgroup, improved survival after the employment of ACE inhibitors was observed. The adverse prognostic significance of female sex might result from a combination of adverse factors (on the one hand a disproportion between the number of VVI pacemakers and indications for this type of pacing, and on the other hand atrial fibrillation and a female predisposition to thromboembolic complications) from a disproportionately small number of antithrombotic therapies.

\section{Study Limitations}

Several limitations of the study should be noted. Firstly, the partially retrospective character of the research and its observational instead of randomized modelling pose a major restriction. Secondly, the missing data on the proportion of right ventricular pacing make it impossible to draw inferences about its prognostic impact. Thirdly, the study lacks data on the precise causes of death. We report only deaths for any reason, the only outcome which we were able to obtain from the National Health fund. Fourthly, we have no data on the prevalence of frailty in our study population.

\section{Acknowledgements}

The study was supported by Medical University of Silesia grant No. KNW-1-106/K/7/K.

\section{References}

1 Forman DE, Rich MW, Alexander KP, Zieman S, Maurer MS, Najjar SS, Cleveland JC Jr, Krumholz HM, Wenger NK: Cardiac care for older adults. Time for a new paradigm. J Am Coll Cardiol 2011;57:1801-1810.

2 Chow GV, Marine JE, Fleg JL: Epidemiology of arrhythmias and conduction disorders in older adults. Clin Geriatr Med 2012;28:539553.

3 Jackson CF, Wenger NK: Cardiovascular disease in the elderly (in English, Spanish). Rev Esp Cardiol 2011;64:697-712.

4 Cherubini A, Oristrell J, Pla X, Ruggiero C, Ferretti R, Diestre G, Clarfield AM, Crome P, Hertogh C, Lesauskaite V, Prada GI, Szczerbinska K, Topinkova E, Sinclair-Cohen J, Edbrooke D, Mills GH: The persistent exclusion of older patients from ongoing clinical trials regarding heart failure. Arch Intern Med 2011;171:550-556.

5 Elizabeth JE, Green GJ: Permanent pacemakers in nonagenarians. Postgrad Med J 1991; 67:663-665.

6 Jahangir A, Shen WK, Neubauer SA, Ballard DJ, Hammill SC, Hodge DO, Lohse CM, Gersh BJ, Hayes DL: Relation between mode of pacing and long-term survival in the very elderly. J Am Coll Cardiol 1999;33:1208-1216.

7 Samet P, Castillo C, Bernstein WH: Hemodynamic consequences of atrial and ventricular pacing in subjects with normal hearts. Am J Cardiol 1966;18:522-525.

8 Kilıçaslan B, Vatansever Ağca F, Kilıçaslan EE, Kınay O, Tigen K, Cakır C, Nazlı C, Ergene O: Comparison of DDD versus VVIR pacing modes in elderly patients with atrio- ventricular block. Turk Kardiyol Dern Ars 2012;40:331-336.

9 Bush DE, Finucane TE: Permanent cardiac pacemakers in the elderly. J Am Geriatr Soc 1994;42:326-334.

10 Vassolo M, Lamas GA: Dual-chamber vs ventricular pacing in the elderly: quality of life and clinical outcomes. Eur Heart J 1999;20: 1607-1608.

11 Sutton R, Bourgeois I: Cost benefit analysis of single and dual chamber pacing for sick sinus syndrome and atrioventricular block. An economic sensitivity analysis of the literature. Eur Heart J 1996;17:574-582.

12 Lamas GA: Pacemaker mode selection and survival: a plea to apply the principles of evidence based medicine to cardiac pacing practice. Heart 1997;78:218-220. 
13 Wong GC, Hadjis T: Single chamber ventricular compared with dual chamber pacing: a review. Can J Cardiol 2002;18:301-307.

14 Schmidt B, Brunner M, Olschewski M, Hummel C, Faber TS, Grom A, Giesler U, Bode C, Zehender M: Pacemaker therapy in very elderly patients: long-term survival and prognostic parameters. Am Heart J 2003;146:908913.

15 Brunner M, Olschewski M, Geibel A, Bode C, Zehender M: Long-term survival after pacemaker implantation. Eur Heart J 2004;25:8895.

16 Connolly SJ, Kerr C, Gent M, Yusuf S: Dualchamber versus ventricular pacing: critical appraisal of current data. Circulation 1996;94: 578-583.

17 Lamas GA, Lee KL, Sweeney MO, Silverman R, Leon A, Yee R, Marinchak RA, Flaker G, Schron E, Orav EJ, Hellkamp AS, Greer S, McAnulty J, Ellenbogen K, Ehlert F, Freedman RA, Estes NA 3rd, Greenspon A, Goldman L: Ventricular pacing or dual-chamber pacing for sinus-node dysfunction. N Engl J Med 2002;346:1854-1862.

18 Andersen HR, Thuesen L, Bagger JP, Vesterlund T, Thomsen PEB: Prospective randomised trial of atrial versus ventricular pacing in sick-sinus syndrome. Lancet 1994;344: 1523-1528.

19 Andersen HR, Nielsen JC, Thomsen PE, Thuesen L, Mortensen PT, Vesterlund T, Pedersen AK: Long-term follow-up of patients from a randomised trial of atrial versus ventricular pacing for sick-sinus syndrome. Lancet 1997;350:1210-1216.

20 Udo EO, van Hemel NM, Zuithoff NP, Kelder JC, Crommentuijn HA, Koopman-Verhagen AM, Voskuil T, Doevendans PA, Moons KG: Long-term outcome of cardiac pacing in octogenarians and nonagenarians. Europace 2012;14:502-508.

21 Lamas GA, Pashos CL, Normand SL, McNeil $B$ : Permanent pacemaker selection and subsequent survival in the elderly Medicare pacemaker recipients. Circulation 1995;91:10631069.

22 Connolly SJ, Kerr CR, Gent M, Roberts RS, Yusuf S, Gillis AM, Sami MH, Talajic M, Tang AS, Klein GJ, Lau C, Newman DM: Effects of physiologic pacing versus ventricular pacing on the risk of stroke and death due to cardiovascular causes. Canadian Trial of Physiologic Pacing Investigators. N Engl J Med 2000; 342:1385-1391.

23 Lamas GA, Orav EJ, Stambler BS, Ellenbogen KA, Sgarbossa EB, Huang SK, Marinchak RA, Estes NA 3rd, Mitchell GF, Lieberman EH, Mangione CM, Goldman L, Griffin JJ, Maloney JD, Rizo-Patrón C, Venditti FJ, Wilkoff BL: Quality of life and clinical outcomes in elderly patients treated with ventricular pacing as compared with dual-chamber pacing. Pacemaker Selection in the Elderly Investigators. N Engl J Med 1998;338:1097-1104.

24 Link MS, Estes NA 3rd, Griffin JJ, Wang PJ, Maloney JD, Kirchhoffer JB, Mitchell GF,
Orav J, Goldman L, Lamas GA: Complications of dual chamber pacemaker implantation in the elderly. Pacemaker Selection in the Elderly (PASE) Investigators. J Interv Card Electrophysiol 1998;2:175-179.

25 Amikam S, Lemer J, Rogiun N, Peleg H, Riss E: Long-term survival of elderly patients after pacemaker implantation. Am Heart J 1976; 91:445-449.

26 Shen WK, Hayes DL, Hammill SC, Bailey KR, Ballard DJ, Gersh BJ: Survival and functional independence after implantation of a permanent pacemaker in octogenarians and nonagenarians. A population-based study. Ann Intern Med 1996;125:476-480.

27 Pyatt JR, Somauroo JD, Jackson M, Grayson AD, Osula S, Aggarwal RK, Charles RG, Connelly DT: Long-term survival after permanent pacemaker implantation: analysis of predictors for increased mortality. Europace 2002;4: 113-119.

28 Lewington S, Clarke R, Qizilbash N, Peto R, Collins R; Prospective Studies Collaboration: Age-specific relevance of usual blood pressure to vascular mortality: a meta-analysis of individual data for one million adults in 61 prospective studies. Lancet 2002;360:1903-1913.

29 Boshuizen HC, Izaks GJ, van Buuren S, Ligthart GJ: Blood pressure and mortality in elderly people aged 85 and older: community based study. BMJ 1998;316:1780-1784.

30 Mattila K, Haavisto M, Rajala S, Heikinheimo $\mathrm{R}$ : Blood pressure and five year survival in the very old. Br Med J (Clin Res Ed) 1988;296: 887-889.

31 Satish S, Freeman DH Jr, Ray L, Goodwin JS: The relationship between blood pressure and mortality in the oldest old. J Am Geriatr Soc 2001;49:367-374.

32 Lane DA, Lip GY: Female gender is a risk factor for stroke and thromboembolism in atrial fibrillation patients. Thromb Haemost 2009; 101:802-805.

33 Di Luozzo G, Shirali AS, Varghese R, Lin HM, Weiss AJ, Bischoff MS, Griepp RB: Quality of life and survival of septuagenarians and octogenarians after repair of descending and thoracoabdominal aortic aneurysms. J Thorac Cardiovasc Surg 2013;145:378-384.

34 Fried LP, Tangen CM, Walston J, Newman AB, Hirsch C, Gottdiener J, Seeman T, Tracy R, Kop WJ, Burke G, McBurnie MA; Cardiovascular Health Study Collaborative Research Group: Frailty in older adults: evidence for a phenotype. J Gerontol A Biol Sci Med Sci 2001;56:M146-M156.

35 Shamliyan T, Talley KM, Ramakrishnan R, Kane RL: Association of frailty with survival: a systematic literature review. Ageing Res Rev 2013;12:719-736.

36 Green AR, Leff B, Wang Y, Spatz ES, Masoudi FA, Peterson PN, Daugherty SL, Matlock DD: Geriatric conditions in patients undergoing defibrillator implantation for prevention of sudden cardiac death: prevalence and impact on mortality. Circ Cardiovasc Qual Outcomes 2016;9:23-30.
37 Culleton BF, Manns BJ, Zhang J, Tonelli M, Klarenbach S, Hemmelgarn BR: Impact of anemia on hospitalization and mortality in older adults. Blood 2006;107:3841-3846.

38 Goodnough LT, Schrier SL: Evaluation and management of anemia in the elderly. Am J Hematol 2014;89:88-96.

39 Bianchi VE: Anemia in the elderly population. J Hematol 2014;3:95-106.

40 Denny SD, Kuchibhatla MN, Cohen HJ: Impact of anemia on mortality, cognition, and function in community-dwelling elderly. Am J Med 2006;119:327-334.

41 Penninx BW, Pahor M, Woodman RC, Guralnik JM: Anemia in old age is associated with increased mortality and hospitalization. J Gerontol A Biol Sci Med Sci 2006;61:474479.

42 Zakai NA, Katz R, Hirsch C, Shlipak MG, Chaves PH, Newman AB, Cushman M: A prospective study of anemia status, hemoglobin concentration, and mortality in an elderly cohort: the Cardiovascular Health Study. Arch Intern Med 2005;165:2214-2220.

43 Deal JA, Carlson MC, Xue QL, Fried LP, Chaves PH: Anemia and 9-year domain-specific cognitive decline in community-dwelling older women: the Women's Health and Aging Study II. J Am Geriatr Soc 2009;57: 1604-1611.

44 Chaves PH, Carlson MC, Ferrucci L, Guralnik JM, Semba R, Fried LP: Association between mild anemia and executive function impairment in community-dwelling older women: the Women's Health and Aging Study II. J Am Geriatr Soc 2006;54:1429-1435.

45 Gianni M, Bosch J, Pogue J, Probstfield J, Dagenais G, Yusuf S, Lonn E: Effect of long-term ACE-inhibitor therapy in elderly vascular disease patients. Eur Heart J 2007;28:13821388.

46 Armaganijan LV, Toff WD, Nielsen JC, Andersen HR, Connolly SJ, Ellenbogen KA, Healey JS: Are elderly patients at increased risk of complications following pacemaker implantation? A meta-analysis of randomized trials. Pacing Clin Electrophysiol 2012;35: 131-134.

47 Vardas PE, Auricchio A, Blanc JJ, Daubert JC, Drexler H, Ector H, Gasparini M, Linde C, Morgado FB, Oto A, Sutton R, Trusz-Gluza $\mathrm{M}$; European Society of Cardiology; European Heart Rhythm Association: Guidelines for cardiac pacing and cardiac resynchronization therapy: the Task Force for Cardiac Pacing and Cardiac Resynchronization Therapy of the European Society of Cardiology. Developed in collaboration with the European Heart Rhythm Association. Eur Heart J 2007; 28:2256-2295.

48 Proclemer A, Ghidina M, Gregori D, Facchin D, Rebellato L, Zakja E, Gulizia M, Esente P: Trend of the main clinical characteristics and pacing modality in patients treated by pacemaker: data from the Italian Pacemaker Registry for the quinquennium 2003-07. Europace 2010;12:202-209. 